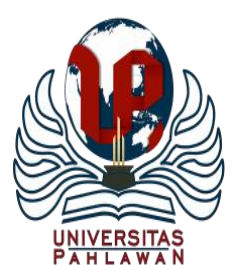

Jurnal Abdidas Volume 2 Nomor 5 Tahun 2021 Halaman 1049-1053

JURNAL ABDIDAS

http://abdidas.org/index.php/abdidas

\title{
Penyuluhan Pendidikan Hukum Tentang Pencegahan Perilaku Kenakalan Remaja
}

\author{
Nopiana Mozin ${ }^{1}$, Rasid Yunus ${ }^{2}$, Zulaecha Ngiu $^{3}$, Haikal Daibaha ${ }^{4}$, Sri Mulyani Patuti ${ }^{5}$, Wahyudin \\ Buheli $^{6}$ \\ Fakultas Ilmu Sosial, Universitas Negeri Gorontalo, Indonesia ${ }^{1,2,3,4,5,6}$ \\ Email: Nopianamozin@ung.ac.id ${ }^{1} \underline{\text { rasidyunus@ung.ac.id }}^{2} \underline{\text { zulaecha.ngiu@ung.ac.id }}^{3}$
}

\begin{abstract}
Abstrak
Perilaku remaja yang sering kali menyimpang dari aturan dan norma yang ada, membuat kenakalan remaja ini pun dianggap menjadi masalah yang genting dan memerlukan penanganan yang tepat. SMKN 5 Gorontalo yang memiliki siswa yang merupakan remaja yang diharapkan sebagai penerus bangsa perlu memiliki pemahahaman dan pengetahuan tentang bahaya dan sanksi yang bisa ditimbulkan akibat kenakalan remaja. Faktor internal dan eksternal seperti ekonomi keluarga dan pergaulan yang salahpun diduga sebagai pemicu kenakalan remaja yang terjadi. Oleh sebab itu diperlukan dukungan dari sekolah khususnya guru melalui berbagai program/kegiatan intra maupun extra kurikuler di SMKN 5 Gorontalo, agar para siswa bisa mengefektifkan waktu untuk mengembangkan minat dan bakat serta terhindar dari perilaku menyimpang yang dapat menyebabkan kenakalan remaja itu sendiri. Selain itu bimbingan dari orang tua pun diperlukan untuk membentuk perkembangan pribadi remaja menuju kedewasaan. Metode yang digunakan dalam kegiatan ini adalah penyuluhan kepada para siswa di SMKN 5 Gorontalo. Hasil dan simpulan dari kegiatan ini adalah untuk membentuk kesadaran diri siswa di SMKN 5 Gorontalo terkait bagaimana mencegah perilaku kenakalan remaja melalui pemahaman dan pengetahuan tentang akibat dan sanksi yang dapat ditimbulkan dari perilaku kenakan remaja tersebut.
\end{abstract}

Kata kunci: pendidkan hukum, kenakalan remaja, pengabdian masyarakat

\section{Abstract}

The behavior of teenagers who often deviate from existing rules and norms makes juvenile delinquency considered a critical problem and requires proper handling. Vocational High School 5 Gorontalo which has students who are teenagers who are expected to be the nation's successors need to have an understanding and knowledge of the dangers and sanctions that can be caused by juvenile delinquency. Internal and external factors such as the family economy and the wrong association are suspected as triggers for juvenile delinquency that occur. Therefore, support is needed from schools, especially teachers through various intra and extra curricular programs/activities at Vocational High School 5 Gorontalo, so that students can make time to develop their interests and talents and avoid deviant behavior that can lead to juvenile delinquency. In addition, guidance from parents is also needed to shape the personal development of adolescents towards adulthood. The method used in this community service is counseling to students at Vocational High School 5 Gorontalo. The results and conclusions of this community service provider are to form self-awareness of students at Vocational High School 5 Gorontalo regarding how to prevent juvenile delinquency behavior through understanding and knowledge of the consequences and sanctions that can be caused by the behavior of these teenagers.

Keywords: legal education, juvenile delinquency, community services

Copyright (c) 2021 Nopiana Mozin, Rasid Yunus, Zulaecha Ngiu, Haikal Daibaha, Sri Mulyani Patuti, Wahyudin Buheli

$\square$ Corresponding author

Address : Universitas Negeri Gorontalo

Email : nopianamozin@ung.a.c.id

ISSN 2721- 9224 (Media Cetak)

DOI $:$ https://doi.org/10.31004/abdidas.v2i5.413 ISSN 2721- 9216 (Media Online) 
1050 Penyuluhan Pendidikan Hukum Tentang Pencegahan Perilaku Kenakalan Remaja - Nopiana Mozin, Rasid Yunus, Zulaecha Ngiu, Haikal Daibaha, Sri Mulyani Patuti, Wahyudin Buheli

DOI: https://doi.org/10.31004/abdidas.v2i5.413

\section{PENDAHULUAN}

Pendidikan merupakan salah satu aspek penting dalam mengembangkan kualitas sumber daya manusia secara berkelanjutan. Pendidikan pun merupakan salah satu upaya untuk meningkatkan kehidupan siswa kearah yang lebih mandiri, berahlak mulia guna terciptanya kehidupan yang lebih baik. Pendidikan yang berkualitas pun menjadi dambaan masyarakat. Khususnya orang tua siswa. Namun saat ini, dunia pendidikan masih belum sepenuhnya memenuhi harapan yang diinginkan oleh masyarakat.

Masyarakat khususnya orang tua siswa mengharapkan pendidikan dapat menjadikan anakanak mereka menjadi berguna pada nusa dan bangsa, namun kenyataannya, masih banyak siswa yang hingga saat ini terjerumus ke dalam masalah sosial yakni perilaku-perilaku menyimpang seperti halnya kenakalan remaja (Kartono, 2017).

Kenakalan remaja dalam bukunya (Aroma, Suminar, 2012) adalah proses penyimpangan perbuatan/perilaku terhadap pelanggaran norma/aturan yang ada. Menurut (Oktawati, 2017) kenakalan remaja adalah pelanggaran norma/aturan hukum yang dilakukan oleh remaja atau dalam masa transisi anak menuju dewasa. Sedangkan menurut (Anggraini, 2017) kenakalan remaja adalah perilaku anti social yang dalam hal ini melanggar norma-norma dan aturan yang berlaku dimasyarakat.

Perubahan fisik, mental bahkan psikologis remaja yang cenderung merasa dibatasi kebebasannya akhirnya melakukan perbuatanperbuatan nakal hingga terjerumus kedalam perilaku menyimpang yang tanpa disadari dapat memberikan efek negatif bagi remaja itu sendiri bahkan dapat berujung kriminalitas dan mengakibatkan tindak pidana (Karlina, 2020).

Beberapa kasus kenakalan remaja yang sering terjadi dan berujung tindak pidana adalah pencurian, tawuran, perampokan, penganiayaan, narkotika hingga yang paling parah sampai melakukan pembunuhan. Kasus kenakalan remaja itupun sering kali disebabkan oleh banyak faktor yakni faktor internal maupun faktor eksternal (Amalia, 2012).

Adapun menurut (Musbikin, 2013), faktorfaktor yang menyebabkan remaja terjerumus kepada perilaku menyimpang (Juvenile Deliquency) yakni; a) pribadi remaja itu sendiri; b) lingkungan masyarakat sekitar; c) faktor lingkungan sekolah; d) faktor ekonomi dan keluarga.

Dari faktor diatas, terlihat bahwa salah satu cara untuk mencegah perilaku kenakalan remaja itu sendiri yakni bisa dilakukan dengan berbagai upaya, baik itu upaya secara preventif maupun upaya represif. Remaja sebagai generasi penerus bangsa, sangat diharapkan agar bisa tumbuh dan berkembang secara baik dan positif oleh sebab itu dibutuhkan penanaman nilai-nilai moral dan pendidikan serta dukungan dari pihak-pihak terkait anatara lain sekolah, guru dan orang tua.

Melihat fenomena sosial yang ada maka pengabdian masyarakat yang dilakukan ini bertujuan untuk meningkatkan kesadaran diri dan wawasan pengetahuan khsusunya siswa di SMKN 5 Gorontalo, agar ke depannya menjadi remaja dan generasi penerus bangsa yang taat akan peraturan dan terhindar dari perilaku kenakalan remaja. 
1051 Penyuluhan Pendidikan Hukum Tentang Pencegahan Perilaku Kenakalan Remaja - Nopiana Mozin, Rasid Yunus, Zulaecha Ngiu, Haikal Daibaha, Sri Mulyani Patuti, Wahyudin Buheli

DOI: https://doi.org/10.31004/abdidas.v2i5.413

\section{METODE}

Metode yang digunakan dalam pengabmas ini adalah berupa penyuluhan pendidikan hukum tentang pencegahan perilaku kenakalan remaja di SMKN 5 Gorontalo. Dalam kegiatan ini kami menganalisis dan mengidentifikasi seberapa besar pengetahuan siswa SMKN 5 Gorontalo terkait perilaku kenakalan remaja, selanjutnya memberikan penyuluhan secara interaktif kepada siswa di SMKN 5 Gorontalo.

Adapun langkah yang dilakukan dalam kegiatan ini yakni memberikan penyuluhan secara interaktif bagi siswa SMKN 5 Gorontalo dengan harapan output yang tercapai yakni terbentuknya kesadaran diri dan meningkatnya pengetahuan serta wawasan siswa SMKN 5 Gorontalo terkait akibat dansanksi yang ditimbulkan dari perilaku kenakalan remaja tersebut.

Kegiatan penyuluhan ini dilaksanakan pada minggu kedua bulan agustus tahun 2021 oleh dosen dan mahasiswa jurusan Ilmu Hukum dan Kemasyarakatan Unversitas Negeri Gorontalo serta dihadiri oleh pihak guru dan siswa SMKN 5 Gorontalo.

\section{HASIL DAN PEMBAHASAN}

Maraknya kasus kenakalan remaja yang sering ditemukan di Gorontalo, biasanya diakibatkan oleh rendahnya tingkat pengetahuan yang ada serta kurangnya hubungan baik dan dukungan dari orang tua dan guru di sekolah, sehingga tak bisa dipungkiri miskomunikasi antara remaja, guru dan orang tua pun terjadi yang akibatnya remaja sering terjerumus kedalam perilaku kenakalan remaja. SMKN 5 Gorontalo khususnya yang memiliki siswa-siswi yang mulai beranjak ke masa transisi inipun tidak lepas dari bahaya kenakalan remaja yang ada. Pemahaman hukum terkait kenakalan remaja yang masih terbilang rendah juga dapat menyebabkan remaja bisa saja terjerumus kedalam perilaku menyimpang, Maka dari itu hal ini wajib menjadi perhatian, khususnya bagi sekolah, guru dan orang tua (Sobur, 2011) untuk dapat mencegah kenakalan remaja di SMKN 5 Gorontalo.

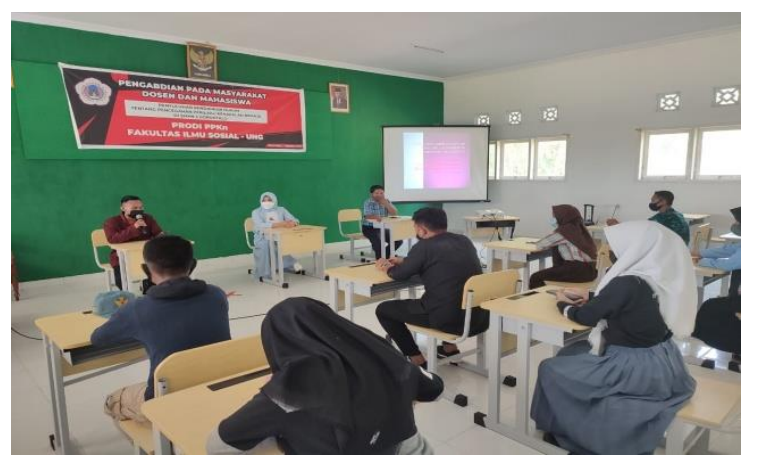

Gambar 1. Pembukaan Kegiatan Penyuluhan

Berdasarkan hal diatas maka pengabmas bekerja sama dengan mahasiswa Jurusan IHK Fakultas Ilmu Sosial Universitas Negeri Gorontalo beserta pihak sekolah, guru dan siswa SMKN 5 Gorontalo mengadakan penyuluhan pendidikan hukum tentang pencegahan perilaku kenakalan remaja di SMKN 5 Gorontalo.

Pengabdian masyarakat ini dilakukan melalui penyuluhan yang dilakukan secara interaktif baik dengan melakukan pemberian edukasi lewat materi yang ditampilkan melalui power point dan tanya jawab langsung kepada siswa SMKN 5 Gorontalo sebagai peserta penyuluhan. Keikutsertaan siswa dalam 
1052 Penyuluhan Pendidikan Hukum Tentang Pencegahan Perilaku Kenakalan Remaja - Nopiana Mozin, Rasid Yunus, Zulaecha Ngiu, Haikal Daibaha, Sri Mulyani Patuti, Wahyudin Buheli

DOI: https://doi.org/10.31004/abdidas.v2i5.413

penyuluhan ini terlihat dari antusiasme siswa menerima materi.

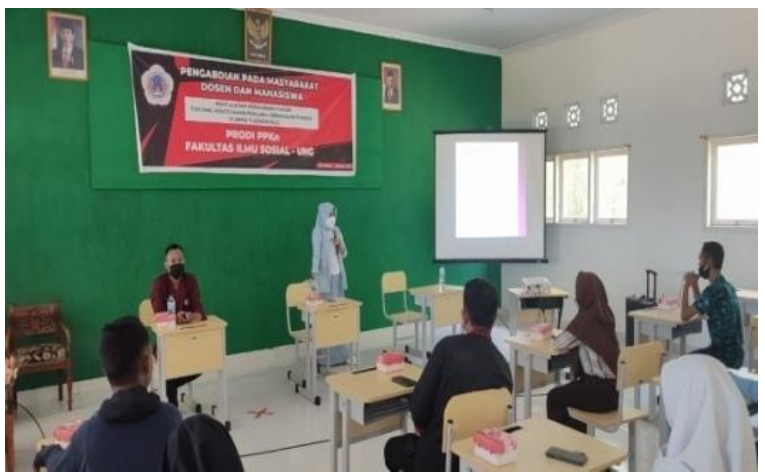

Gambar 2. Sesi Tanya Jawab

Sebelum dilaksanakan kegiatan pengabdian masyarakat ini, pihak SMKN 5 Gorontalo melalui kegiatan belajar mengajar selalu berusaha untuk menanamkan pendidikan moral sosial dan agama pada anak didik. Namun akibat miskomunikasi antara siswa guru dan juga orang tua, anak seringkali terjebak melakukan hal negatif yang berdampak pada diri remaja itu sendiri. Oleh sebab itu kami mencoba melakukan koordinasi dengan pihak guru dan sekolah di SMKN 5 Gorontalo untuk selanjutnya mengadakan penyuluhan pendidikan hukum bagi para siswa di SMKN 5 Gorontalo, guna mencegah perilaku kenakalan remaja. Adapun penyuluhan ini bersifat interaktif terkait sejauh mana pengetahuan siswa khsusunya di SMKN 5 Gorontalo, terkait akibat dan sanksi hukum yang bisa menjerat pelaku kenakalan remaja.

Hasil dari penyuluhan tersebut adalah terbentuknya kesadaran diri dan meningkatnya pemahaman hukum oleh siswa khususnya di SMKN 5 Gorontalo terkait kenakalan remaja, sehingga para siswa dapat menjalin lagi komunikasi yang baik dengan guru dan orang tua guna terhindar dari perilaku menyimpang tersebut.

\section{SIMPULAN}

Berdasarkan pelaksanan kegiatan ini dapat disimpulkan kegiatan pengabmas "Penyuluhan Pendidikan Hukum Tentang Pencegahan Perilaku Kenakalan Remaja di SMKN 5 Gorontalo" telah terlaksana sesuai dengan dicitakan. Mahasiswa Jurusan IHK Fakultas Ilmu Sosial UNG besertapihak guru dan siswa SMKN 5 Gorontalo yang terlibat didalamnya turut berkontribusi dan berperan dalam kegiatan hingga akhir kegiatan penyuluhan ini.

\section{UCAPAN TERIMA KASIH}

Pelaksanaan pengabmas ini, tidak luput dan tidak lepas dari ikut serta berbagai pihak dalam hal bantuan dan dukungan, sehingga kami ingin mengucapkan terima kasih kepada pihak sekolah, guru dan siswa di SMKN 5 Gorontalo yang telah turut mensukseskan pelaksanaan kegiatan ini.

\section{DAFTAR PUSTAKA}

Amalia, R. (2012). Pengaruh Kecerdasan Emosi dan Kuaalitas Hubungan Dengan Orang tua Terhadap Kenakalan Remaja : Studi Pada siswa SMK Negeri 1 Pujon Kabupaten Malang. Retrieved Agustus 20, 2021, from Electronic Theses Universitas Islam Negeri Maulana Malik Ibrahim Malang: http://etheses.uin-malang.ac.id/2253/

Anggraini, Y. (2017). Hubungan Fungsi Afektif Keluarga Dengan PerilakuKenakalan Remaja di SMK Cendana Padang Panjang Tahun 2016. Jurnal Menara Ilmu Volume 11 Nomor $76,155-165$.

Aroma, Suminar. (2012). Hubungan Antara Tingkat Kontrol Diri dengan Kecenderungan Perilaku Kenakalan Remaja. Jurnal Psikologi 
1053 Penyuluhan Pendidikan Hukum Tentang Pencegahan Perilaku Kenakalan Remaja - Nopiana Mozin, Rasid Yunus, Zulaecha Ngiu, Haikal Daibaha, Sri Mulyani Patuti, Wahyudin Buheli

DOI: https://doi.org/10.31004/abdidas.v2i5.413

Pendidikan dan Perkembangan Volume 1 Nomor 2, 1-6.

Karlina, L. (2020). Fenomena Terjadinya Kenakalan Remaja. Jurnal Edukasi Non Formal , 1-12.

Kartono. (2017). Kenakalan Remaja (Patologi Sosial2). Jawa Barat: Raja Geafindo Persada.

Musbikin, I. (2013). Mengatasi Kenakalan Siswa Remaja. Pekanbaru: Zanafa Publishing.

Oktawati, W. (2017). Kenakalan Remaja di Desa Sungai Paku ((Studi Kasus SMP 4 Kampar Kiri Kabupaten Kampar). Jurnal Online Mahasiswa FISIP Volume 4 Nomor 2 , 1-15.

Sobur, A. (2011). Komunikasi Orang Tua dan Anak. Bandung: Angkasa. 